\title{
Wie nah ist Du?
}

_ Physiotherapeuten sind nette Menschen, die ich gerne um mich habe. Sie teilen häufig meine Interessen, sind offene Charaktere, und Humor haben auch die meisten. Ich bin mit vielen von ihnen befreundet. Und auch, wenn es nicht bis zur Freundschaft reicht, duze ich viele. Es gibt eine kollegiale Nähe, und das, obwohl ich jetzt Redakteurin bin. Einmal Physiotherapeut - immer Physiotherapeut! Ich genieße das „Du“ und bin schnell dafür zu haben.

_ Und dennoch ist es für mich selbstverständlich, nicht jeden Therapeuten gleich zu duzen. Ich stelle mich mit vollem Namen vor und warte ab, was für eine „Beziehung" wir wohl führen werden. Damit bin ich vermutlich spießig, vielleicht altmodisch, aber immer auf der sicheren Seite. Ein gutes Gefühl - vor allem wenn ich im Laufe des Gesprächs feststelle, dass ich mein Gegenüber gar nicht so sehr mag, und Distanz wahren möchte.

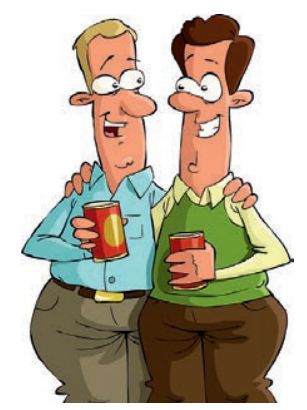

_ Noch klarer war die Situation für mich, wenn ich auf Patienten traf. Für ein „Sie“ hatte ich zahlreiche gute Gründe. Umso erstaunter war ich, als ich in unserem Pro E Kontra las, dass ein Therapeut ebenso viele Argumente für das Duzen von Patienten vorbringen kann (๑S. 51). Dennoch glaube ich, dass ich als Patientin das Siezen bei ihm bevorzugen würde, als Kollegin würde ich diesem Therapeuten aber vermutlich kein $\mathrm{Du}$ verwehren ...

_ Herzlichst, Ihre und Eure

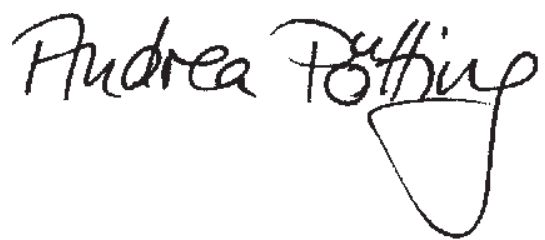

Wer sich duzt, ist sich nah! Ja, aber wollen das all deine - ähhh - Ihre Patienten?

\section{ZU GEWINNEN}

In jeder physiopraxis werden attraktive Gewinne verlost. Möchten Sie einen ergattern, klicken Sie unter www.thieme.de/physiopraxis auf Gewinnspiel.

Und das gibt es in dieser Ausgabe zu gewinnen:

\section{Kursplatz}

1 Kursplatz „Triggerpunkt-

Therapie“" Modul 1

Bücher

2-mal „Assessments in der Rehabilitation; Band 1:

Neurologie“"

und außerdem

1 Jahresabonnement der

Zeitschrift "neuroreha“

1ne Kinder-Yoga-Matte

Seite 10

1 anatomisches

HWS-Modell 